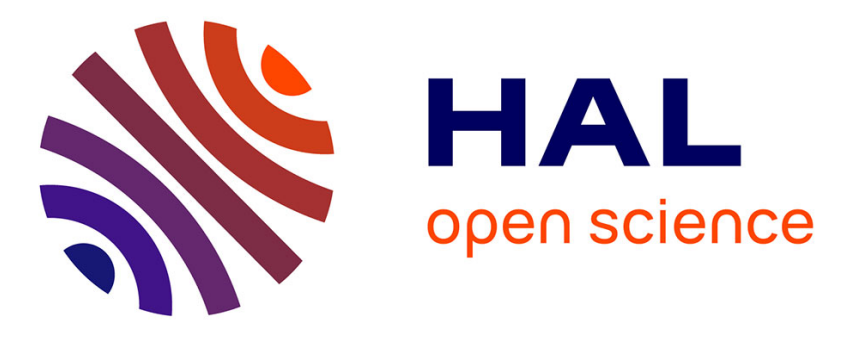

\title{
Mechanical properties of fused sagittal sutures in scaphocephaly
}

Pascal Swider, Franck Delanoé, Florian Jalbert, Sergio Boetto, Pauline

Assemat, Erik Estivalèzes, Frédéric Lauwers

\section{To cite this version:}

Pascal Swider, Franck Delanoé, Florian Jalbert, Sergio Boetto, Pauline Assemat, et al.. Mechanical properties of fused sagittal sutures in scaphocephaly. Clinical Biomechanics, 2021, 86, pp.105369. 10.1016/j.clinbiomech.2021.105369 . hal-03382268

\section{HAL Id: hal-03382268 \\ https://hal.science/hal-03382268}

Submitted on 18 Oct 2021

HAL is a multi-disciplinary open access archive for the deposit and dissemination of scientific research documents, whether they are published or not. The documents may come from teaching and research institutions in France or abroad, or from public or private research centers.
L'archive ouverte pluridisciplinaire HAL, est destinée au dépôt et à la diffusion de documents scientifiques de niveau recherche, publiés ou non, émanant des établissements d'enseignement et de recherche français ou étrangers, des laboratoires publics ou privés. 


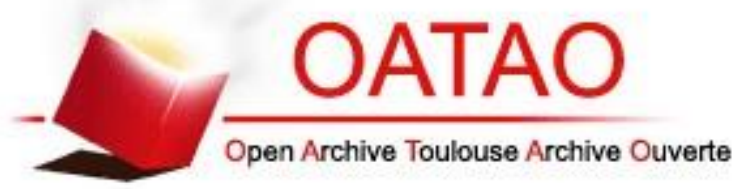

\section{Open Archive Toulouse Archive Ouverte}

OATAO is an open access repository that collects the work of Toulouse researchers and makes it freely available over the web where possible

This is an author's version published in: http://oatao.univ-toulouse.fr/27786

\section{Official URL:}

https://doi.org/10.1016/j.clinbiomech.2021.105369

\section{To cite this version:}

Swider, Pascal and Delanoé, Franck and Jalbert, Florian and Boetto, Sergio and Assemat, Pauline and Estivalèzes, Erik and Lauwers, Frédéric Mechanical properties of fused sagittal sutures in scaphocephaly. (2021) Clinical Biomechanics, 86. 105369. ISSN 0268-0033

Any correspondence concerning this service should be sent to the repository administrator: tech-oatao@listes-diff.inp-toulouse.fr 


\section{Journal Pre-proof}

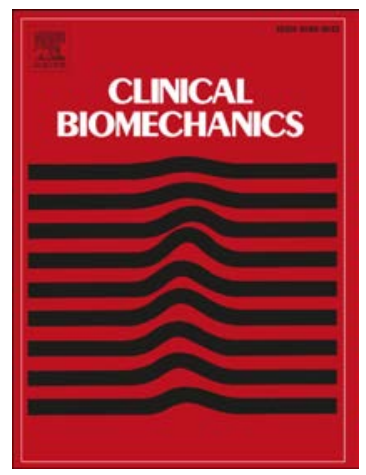

P. Swider, F. Delanoë, F. Jalbert, S. Boetto, P. Assemat, E. Estivalèzes, F. Lauwers

PII: $\quad$ S0268-0033(21)00099-1

DOI: $\quad$ https://doi.org/10.1016/j.clinbiomech.2021.105369

Reference: $\quad$ JCLB 105369

To appear in: $\quad$ Clinical Biomechanics

Received date: $\quad 8$ January 2021

Accepted date: $\quad 23$ April 2021

Please cite this article as: P. Swider, F. Delanoë, F. Jalbert, et al., Mechanical properties of fused sagittal sutures in scaphocephaly, Clinical Biomechanics (2018), https://doi.org/ 10.1016/j.clinbiomech.2021.105369

This is a PDF file of an article that has undergone enhancements after acceptance, such as the addition of a cover page and metadata, and formatting for readability, but it is not yet the definitive version of record. This version will undergo additional copyediting, typesetting and review before it is published in its final form, but we are providing this version to give early visibility of the article. Please note that, during the production process, errors may be discovered which could affect the content, and all legal disclaimers that apply to the journal pertain.

(C) 2018 (C) 2021 Published by Elsevier Ltd. 


\section{Mechanical properties of fused sagittal sutures in scaphocephaly}

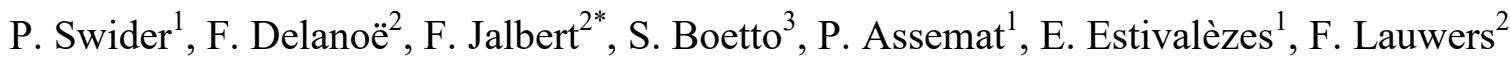

${ }^{1}$ IMFT UMR 5502, Toulouse University, France

${ }^{2}$ Maxillo-facial Surgery Department, Toulouse University Hospital, France

${ }^{3}$ Neuro-surgery Department, Toulouse University Hospital, Fra.'e

Word count: 2546; Figure count: 5; Table count: 0

Abstract word count: 246

Keywords: scaphocephaly, craniosynost s. ', 'iomechanics, mechanobiology, paediatrics, morphogenesis.

Corresponding author:

Professor Pascal Swider

IMFT UMR 5502 CNRS - IN PT - Toulouse 3

2 allées C. Soula

31400 Toulouse cedex

France

Tel. no.: +33 (0)561 497944

Fax no.: +33 (0)561496745

email: pascal.swider@imft.fr

* currently employed at Clinique Pasteur, 45 Avenue de Lombez - BP 27617 - 31076 Toulouse, France. 


\section{$\underline{\text { Abstract }}$}

Background: Craniosynostosis in newborns is caused by the premature closure of the cranial sutures leading to cranial vault deformity. It results in aesthetic imbalance and developmental disabilities and surgery is frequent during the first months of growth. Our study focused on scaphocephaly defined as the premature closure of the sagittal suture. We hypothesised that the effective mechanical properties of sutures were altered as compared to those of the parietal adjacent tissue considered as control.

Methods: The population consisted of seven males and four frmaıs (mean age 4.9 months). Sixteen suture samples and thirty-four parietal tissue sa nples were harvested during corrective surgery and investigated by using three-point $\mathrm{u} \cdot$ nding tests to obtain the structure-

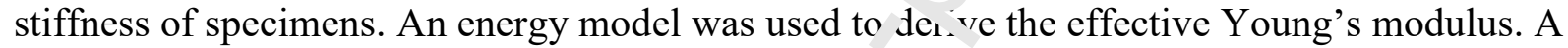
histological study complemented the experime ita $n$ otocol.

Findings: Fused sutures were thicker than $\approx$ djacent bone and the natural curvature of sutures did not influence the static mechanı 1 response. The stiffness of stenotic sutures was significantly higher than that of th $\sim \mathfrak{p}_{\mathfrak{c}} \cdot \dot{*}$ ital bone. The effective Young's modulus of stenotic sutures was significantly lowt. than that of the parietal adjacent tissue. The parietal tissue showed a parallel bone arrhiı $\cdots$ ure whereas the central stenotic tissue was disorganised with more vascularisation.

Interpretation: The stenotic suture differed in structural and mechanical terms from the adjacent bone during calvarial growth in the first year of life. Our study emphasised the alteration of effective tissue properties in craniosynostosis.

Keywords: scaphocephaly, craniosynostosis, biomechanics, mechanobiology, paediatrics, morphogenesis. 


\section{1 - Introduction}

Cranial growth is affected by fluid pressure and forces exerted by internal organs, such as the brain, ocular globes and cephalic muscles. The cranial vault initially consists of single layers of membranous bones and relative sutures. The monolayer tissue is progressively replaced by a layered tissue, consisting in two layers of cortical bones developed from periosteal apposition and located on both sides of a spongy bone structure, the diploë (Couly 1991). The anisotropy of material properties depends on tissue fibre orientation (McPherson and Kriewall 1980). The pattern of bone fibres in paediatric $\mathrm{c}^{-1} \mathrm{v} \mathrm{a}_{\mathbf{1}}: \mathrm{al}$ emanates radially from the ossification centres on each cranial plate.

Cranial growth in utero and during early childhord 1u correlated to brain growth and is enabled by the permeability of cranial sutures. Cra ios? craniofacial deformity due to the premature us on of one or several calvarial sutures. The incidence of this pathology has been est. na ed to be approximately 1 in 2500 births (Slater et al. 2008).

The active underlying brain gre $\cdots$ th $\lambda^{*}$ ctates the passive growth of the skull along the suture line (Couly 1991). In 1890, ' 'irchow (Persing et al. 1989) was the first to explain that premature fusion of these " ures induced abnormal growth patterns of the skull. $\mathrm{He}$ concluded that tissue $g_{1}$ 'wın perpendicular to the suture was restricted while compensatory growth occurred on the rest of the calvaria. This concept is still broadly endorsed today. The impaired sutures determine a specific pathological skull pattern (Persing et al. 1989). Subsequent investigations lead to a classification of deformations (Sear 1937, Montaut and Stricker 1977).

Our study focuses on scaphocephaly, defined as the premature fusion of the sagittal suture. Sagittal synostosis is the most prevalent form with $50 \%$ of craniosynostosis, followed by metopic, coronal and lambdoid synostosis. Synostosis and uneven cranial growth, as 
illustrated in Figure 1a, results in an aesthetic imbalance which may induce developmental disability (Van der Vlugt et al. 2012). Correction of the shape and size of the skull is attained via surgery and most procedures are performed through bicoronal incisions preceding large cranial reshaping. Recently, a novel approach based upon a minimally invasive endoscopic procedure has been developed (Jimenez and Barone 2000, Jimenez et al. 2002). A single resection of the sagittal suture and adjacent bone is performed at the top of the cranium. After surgery, head molding is performed with custom-made helmets, and the cranial vault recovers its harmonious curvature thanks to the osteogenic potential of tha arra.

The mechanism of premature synostosis of suture in 10. syndromic craniosynostosis is multifactorial and unknown (Morris-Kay and Wilkie ? ?5). Gene receptors and fibroblast growth factors are involved in syndromic faciocrani ssy. nstosis (Clarke et al. 1996) whereas non-syndromic context is not well documenter. (ar.aglia et al. 1999). Factors contributing to in-utero constraints include heavy weigh. $(s$, eater than $4 \mathrm{~kg})$ and large size at birth as well as increased maternal age older than 35 yu.rs old (Sanchez-Lara et al. 2010, Oppenheimer et al. 2012).

It appears that mechanicai aspects might play a significant role in the aetiology of

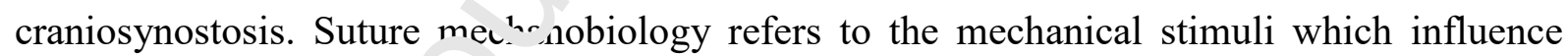
suture growth. Brain gi w wn and intracranial pressure play a key role. Some animal models have highlighted the role of cyclic forces on facial sutures (Delashaw et al. 1991, Kopher et al. 2003) as well as gene activation and transcription factors, showing increased protein synthesis of collagen (Mao et al. 2003).

Although bone tissue mechanical properties have been investigated in numerous studies, there are not many studies conducted on the cranium (Jaslow 1990, Motherway et al. 2009, Maloul et al. 2013). Literature is lacking contributions relating to bone material properties of the foetus, the newborn and the infant. The results present a plethora of discrepancies because 
of morphological variability, difficulties in harvesting paediatric biological tissue and varying experimental methodologies. Calvarial materials for foetal head molding during vaginal delivery have been examined. Three-point bending tests been mostly used in quasi-static or dynamic studies to investigate the response to impact (Coats and Margulies 2006).

Cranial sutures increase in complexity as they grow and interdigitate, hence the evolving mechanical properties show significant variability (Herring 2008). Appraisal of the childbirth process, (McPherson and Kriewall, 1980) showed that suture elastic moduli were lower than those of adjacent osseous shells in one-year-old babies. Mary lies and Thibault, 2000 reported paediatric cranial elastic modulus twelve times $1 \mathrm{Jw}^{-}$than that of the adult cortical calvarial bone. Coats and Margulies, 2006, found " correlation between strain-ratedependency and age, which underlined the viscoelast $c \mathrm{c}$ haviour of cranial tissue.

Normal calvarial and cranial bone displ ‘y, $\mathrm{d}$ elevant variations in their mechanical properties, depending upon patient age $\urcorner n^{\prime}$. tissue location on the cranial vault (Coats and Margulies 2006). The elasticity modul of sutures were lower than those of bone for children aged one week and it was observe ${ }^{\lambda}$ th. ${ }^{+}$issue immaturity was associated with low stiffness at this age.

Investigations carried nit r. sutures showed that normal sutures were characterised by well-organised and unı ${ }^{i}$ rectionally oriented collagen fibres, whereas pathological sutures showed anarchic micro-architectures which, as revealed by a complex ultra-structural arrangement (Anderson et al. 2006). Furthermore, pathological sutures were considerably thicker with some osseous connections between adjacent osseous shells and synostotic sutures were only partially fused but varied in their extent (Regelsberger et al. 2010). The combination of micro-architecture topology with tissue mechanical properties results in the local structural stiffness of the suture, which is predominantly governed by mineralised fraction. The newly formed tissue and its space distribution govern the mechanical response 
of sutures and cranial growth. These aspects have never been investigated in scaphocephalic newborns and could play a significant role in the pathological process.

In this study, we hypothesised that the effective mechanical properties of sutures in a scaphocephalic infant population were altered as compared to those of parietal adjacent tissue considered as control.

\section{2 - Material and methods}

\subsection{Specimen collection}

The collection of biological specimens was performe $\lambda_{1}$ accordance with the protocol approved by the Ethics Committee of Toulouse Univers1ı, Hospital. Children suffering from scaphocephaly were aged between 4 and 7 months at su $_{1}$ rery (mean age equal to 4.9 months); the gender ratio was 7 males and 4 females. Fle, ar sagittal suture specimens were harvested during endoscopic surgery. The explani, w re harvested en bloc as shown in Figure 1a and Figure 1b. As illustrated in Figure 1c, $\mathrm{t}_{\mathrm{s}}>$ thicker central part constituted the pathologic suture and the two symmetrical thinner $\mathrm{f}^{-r}$ ts ${ }^{*}$ ere the parietal plates considered as control. The local reference framework and geon. 'trical parameters $l$ and $\delta$ describing the natural curvature are detailed in Figure 1c. During _. rgery, explants were kept in a 4\% formalin solution and later stored at $-18^{\circ} \mathrm{C}$. Two hu 'rs were required for thawing prior to conducting the experimental procedures on the explants. First, the remaining periosteum on the external part was removed. The explants were subdivided into slender beams parallel to the longitudinal axis of the resected tissue, as shown in Figure 1b. Each specimen was cut by using a high-speed rotary tool $\left(\right.$ Dremel ${ }^{\circledR}$, Racine, WI) equipped with a diamond wheel. Care was taken to obtain a uniform thickness sample calibrated by using a digital caliper. The slenderness ratio was between 10 and 15. 
A histological study was performed on frontal slices perpendicular to the suture. The specimens were entirely fixed in formaldehyde, embedded in paraffin wax and stained with haematoxylin and eosin.

\subsection{Analytical mechanical model for test interpretation}

Width, thickness, mid-length, shear coefficient and natural curvature of specimen were $b$, $h, l, s$ and $\delta$, respectively. The three-points bending test described in Figure 2 shows the pinned-pinned boundary conditions and the force $F$ applied $r_{\ldots}$ the convex side and then on the concave side of the specimen. The test output $\mathrm{m} f \mathrm{asu}_{2}$ ? was the specimen effective stiffness $K$ obtained by applying a linear fitting of the f ${ }^{-m} \mathrm{cu}$ deflection response, i.e. $F / V$. This

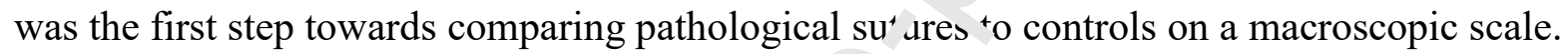

Although bending was predominant, the con: :' $^{\prime}$ ution of shear and traction/compression due to natural curvature had to be cos si sered to derive the complete expression of the effective Young's modulus $E$. As expı ined in detail in the appendix, the strain energy $U$ described by equation (1a) was $\therefore$ on once with respect to $F$ to obtain $E$ knowing $F$, deflection $V$ and the specime. properties, as expressed by equation (1b). Modulus $E$ is proportional to the specim $=n$ s.i.fness $K$ with $\lambda$ detailed in the appendix.

$$
\begin{aligned}
& U=\int_{\alpha_{A}}^{\pi / 2}\left[\frac{12}{h^{2}} M_{z}^{2}(\alpha)+\frac{2\left(1+\frac{\left.{ }^{\prime}\right)}{s}\right)}{s} T_{y}^{2}(\alpha)+N_{x}^{2}(\alpha)\right] \frac{r}{E b h} d \alpha \\
& E=\frac{\lambda}{16 \cdot b \cdot h^{3} \cdot s \cdot \delta^{3}\left(\delta^{2}+l^{2}\right)}\left(\frac{F}{V}\right)
\end{aligned}
$$

\subsection{Experimental study}

The experiments were conducted on a tensile testing machine (Instron 3366®, software Bluehill ${ }^{\circledR}$, Norwood, MA USA). Measurements were taken at room temperature and specimens were kept moist with saline solution. The span of sample supports ranged from 10 
to $30 \mathrm{~mm}$ to adapt to sample length. Three preloading cycles were applied and artefacts, because of time-dependent properties, were suppressed by fixing the displacement rate at 5 $\mathrm{mm} / \mathrm{min}$. The specimens were tested in a linear-elastic domain. Force $F$ was applied on the concave surface then on the convex surface of the specimens to assess the influence of preloading and asymmetrical behaviour due to the natural curvature of samples. In both tests, force and defection $V$ were registered with $10 \mathrm{~Hz}$ sampling frequency.

In the population of eleven patients, fifty specimens were harvested in explanted cranial sutures. Thirty-four were parietal adjacent tissue and sixteen wc-e harvested from central sutures. Sample size with a confidence interval of $95 \%$ ar $\mathbf{d}$ a' admissible error of $15 \%$, lead to a statistical power of $45 \%$. Deviations compared to n ( Ju' 'Issian distribution were admissible and the $t$-test was used with $p<0.05$.

\section{3 - Results}

Geometrical properties of tissue specimıns:

Measurements of mean (SD) in $\eta n$. vere as follows: $l=30.4(10), b=6.3(1.9)$ and offset $\delta=1.05(0.95)$. The heights oi entral stenotic sutures and adjacent parietal tissue were $h=$ $2.65(0.84)$ and $h=2.05\left(n \gamma_{\iota}^{\prime}\right)$, respectively. The thickness difference was significant with $p$ $\leq 0.006$.

\section{Tissue mechanical properties}

The measurements of mean (SD) of effective stiffness $K$ in $\mathrm{N} / \mathrm{mm}$ were as follows: stenotic sutures $K=12.9$ (1.4) and parietal adjacent tissue $K=3.96(0.58)$. The difference was significant with $p \leq 0.005$. The force-displacement responses of two samples for pathological sutures and controls are outlined in Figure 2c.

Effective Young's modules obtained from equation (1b) are shown in Figures $3 a$ and Figure 4a for control tissue and pathological tissue, respectively. The complex anatomy of 
some stenotic sutures explains truncated data for patients \#3, \#4, \#5 and \#8. The mean effective Young's modules in MPa were for stenotic sutures $E=940$ (590) with the force applied on the convex side and $E=890$ (583) with the force applied on the concave side. For the control, it was $E=1400(600)$ with the force applied on the convex side and $E=1678$ (733) with the force applied on the concave side. The moduli obtained on the concave and convex sides displayed no significant differences for both pathological sutures $(p=0.39)$ and the parietal adjacent tissues $(p=0.4)$ used as control, as shown in Figures $3 \mathrm{~b}$ and $4 \mathrm{~b}$ with correlation coefficients of 0.92 and 0.94 , respectively. The $\mathrm{e}^{f f_{a}} \mathrm{ci} \cdot \mathrm{ve}$ modulus of pathologic sutures was lower than that of adjacent tissue with $p<0.0 \Gamma_{1}$.

The natural curvature of the sample had no impart $o_{1}$. this result since the responses on concave side and on the convex side yielded similar cores with $p=0.007$ and 0.0005 , respectively. Moreover, it appears that the eff cc ve Young's modulus expressed by equation (1b) involves the effective Poisson ratic $v$ since shear is considered. It was confirmed that varying $v$ between 0 and 0.49 , with $s$ : xed to $5 / 6$ for rectangular cross-section, induced a relative variation of $E$ lower than $1 \%$ r or $E$ evaluation, $v$ was selected as equal to 0.3 .

\section{Histology}

The histological study $u_{-} \cdot t_{1}$ med that the pathological sutures were thicker than the parietal adjacent structure. Figur 5a shows the parallel bone architecture of parietal adjacent tissue with considerable densification of the inner wall. Conversely, figure $5 \mathrm{~b}$ shows a disorganised tissue pattern of the central stenotic suture. This structure presented greater vascularisation and haematopoietic tissue as compared to the adjacent parietal bone.

\section{4 - Discussion and conclusion}


We put together a homogeneous group of eleven children suffering from scaphocephaly and we initially hypothesised that the effective mechanical properties of sutures were altered as compared to the parietal tissue considered as control. During surgery, the resected sagittal sutures were kept and the mechanical responses of stenotic suture and parietal adjacent tissue were characterised by using a standardised analytical and experimental protocol. To our knowledge, no study in literature is currently investigating the structural properties of fused sutures in craniosynostosis.

Three-point bending tests were implemented with shenr w"tefacts reduced by the slenderness ratio and negligible effects due to pinned-pi ${ }^{\prime}$ ne $^{\prime}$ boundary conditions. Tension tests could have given the effective Young's modulus nt .he tissue, however, given the small size and natural curvature of the explanted specimen', $c_{1}$ mping jaws would have interfered in the measurement process. Indeed, the latter $w, u \cdot r$ rave caused significant initial prestressing to realign specimen and uncontrolled $\sim \mathrm{u}$, ling effects in order to determine the effective modules. Compressive tests would be 11 ?dequate.

The fraction of mineralised tiss $\cdots$ i. stenotic sutures and controls was significant and their contribution to stiffness and efi' 'ctive material volume was predominant. Therefore, the effect of process conservation was $\sim_{i}$ impactful, as confirmed by preliminary tests conducted on some fresh samples.

It was confirmed that the natural curvature of suture did not show any significant impact on strain energy, local structural stiffness and finally on the effective Young's modulus of the tissue. The moduli of stenotic sutures were lower than those of the parietal tissue, which was quite similar similar to normal bone. Eight pieces were conserved in formalin and three were conserved in frost. The two conservation methods had negligible effects in line with previous studies showing the limited impact of conservation conditions on the macroscopic mechanical properties of bone tissue (Nazarian et al. 2009; Berteau et al. 2013). 
The standard deviation of experimental effective moduli was significant due to the variation in suture thickness. Even if the width and length of the samples were controlled by the experimental protocol, thickness variation was patient-dependent and clinically relevant. This variation is documented in literature (Coats and Margulies 2006) and interpretation can be supported by equation (1b). Indeed, modulus is proportional to stiffness variation and about three times more sensitive to thickness variation. This explains the increase in stiffness associated with tissue alteration. Lastly, it appears that stiffness as local structural property of sutures and effective Young's modulus as tissue intrinsic pror $\cdots$ ty are complementary with a view to exploring the biomechanical behaviour of the in vi vo - iture.

The histological analysis indicated a radial fibres distrlu 'tion in the parietal tissue samples, significant loss of parallel architecture and increaser in` rstitial tissue inside the pathological suture. The alteration of the effective modulus oi notic sutures could be associated with the disorganised anisotropic tissue micro-an hi† cture (McPherson and Kriewall 1980, Anderson et al. 2006).

In conclusion, we found that the renotic suture remained different, in structural and mechanical terms, from the acij cen $i$ bone during calvarial growth in the first year of life, as aligned with our central hrno he sis.

In one sense, the rela inships between structure and effective mechanical properties were obtained at the macroscopic level wit respect to the specimens. In further studies, a multiscale modelling approach (Shipley and Chapman, 2010; Davit and Quintard, 2017) could be considered to explore how these dissimilarities in architecture result in different mechanical properties. To this end, at least two major problems need to be solved, namely the identification of mechanical properties varying at the microscale and the implementation of a reliable numerical method able to perform structural equations upscaling from a complex and heterogeneous microarchitecture. 
Other local factors such as metabolic factors or vascularisation were not taken into account during data collection as they might impact the in-vivo growth environment. We targeted the resulting mechanical determinants so as to offer a contribution to the aetiology of craniosynostosis.

\section{Acknowledgements:}

We are deeply grateful to Professor Anne Gomez-Brouchet from IUCT, Toulouse University Hospital, France, for providing the histological data.

\section{References:}

Anderson P, Netherway D, David D, Self P. 2006. Scaı ning electron microscope and microCT evaluation of cranial sutures in health a d is ase. Journal of Craniofacial Surgery. 17: 909.

Berteau JP, Baron C, Pithioux M, Lu'nay F, Chabrand P, Lasaygues P. 2013. In vitro ultrasonic and mechanic charartari ${ }^{\cdots}$ ion of the modulus of elasticity of children cortical bone. Ultrasonics. doi: 10.1C 6 .

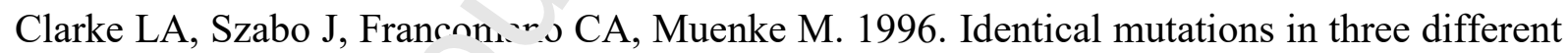
fibroblast growth fack $r$ receptor genes in autosomal dominant craniosynostosis syndromes. Nature Genetics. 14(2):174-6.

Coats B, Margulies SS. 2006. Material Properties of Human Infant Skull and Suture at High Rates. J. Neurotrauma. 23:1222-1232.

Couly G. 1991. Développement céphalique. Wolters Kluwer France.

Delashaw JB, Persing JA, Jane JA. Cranial deformation in craniosynostosis. A new explanation. Neurosurg Clin N Am. 1991;2(3):611-620. 
Davit Y, Quintard M. 2017. Technical Notes on Volume Averaging in Porous Media I: How to Choose a Spatial Averaging Operator for Periodic and Quasiperiodic Structures. Transp Porous Med. 119: 555-584.

Herring SW. 2008. Mechanical influences on suture development and patency. Front Oral Biol. 12: 41-56.

Jaslow CR. Mechanical properties of cranial sutures. 1990. Journal of Biomechanics. 23: $313-321$.

Jimenez DF, Barone CM, Cartwright CC, Baker L. $\left.n^{n}\right)_{L}$. Early management of craniosynostosis using endoscopic-assisted strip craniec on es and cranial orthotic molding therapy. Pediatrics. 110, 97-104.

Kopher RA, Nudera JA, Wang X, O'Grady K, Mai JJ. 2003. Expression of in vivo mechanical strain upon different wave for $n_{s} n^{f}$ exogenous forces in rabbit craniofacial sutures. Ann Biomed Eng. 31: 1125-1:31.

Maloul A, Fialkov J. Whyne CM. 2013. Characterization of the bending strength of craniofacial sutures. Journal of Dio1`chanics. 46, 912-917.

Mao JJ, Wang X, Kopher iA 2003. Biomechanics of craniofacial sutures: orthopedic implications. The Angle on hr dontist.73: 128-135.

Margulies SS, Thibauı KL. 2000. Infant skull and suture properties: measurements and implications for mechanisms of pediatric brain injury. J Biomech Eng 122: 364-371.

McPherson GK, Kriewall TJ. 1980. The elastic modulus of fetal cranial bone: A first step towards an understanding of the biomechanics of fetal head molding. Journal of Biomechanics. 13: 9-16.

Montaut J, Stricker M. 1977. Les dysmorphies craniofaciales. $27^{\text {th }}$ annual congress of the french neuro-surgery society. Masson editor. 
Morriss-Kay G, Wilkie A. 2005. Growth of the normal skull vault and its alteration in craniosynostosis: insights from human genetics and experimental studies. Journal of anatomy. 207: 637-653.

Motherway JA, Verschueren P, Perre GVD, Sloten JV, Gilchrist MD. 2009. The mechanical properties of cranial bone, the effect of loading rate and cranial sampling position. Journal of Biomechanics. 42: 2129-2135.

Nazarian A., Hermannsson BJ, Muller J, Zurakowski D, Snyder BD. 2009. Effects of tissue preservation on murine bone mechanical properties. Journal $\sim$ f bi jmechanics. 42, 82-86.

Oppenheimer AJ, Rhee ST, Goldstein SA, Buck ma' SR. 2012. Force-induced craniosynostosis via paracrine signaling in the murine sgittal suture. J Craniofac Surg 23: 573-577 (2012).

Persing JA, Jane JA, Shaffrey M. 1989. Virch su ar $\mathfrak{d}$ the pathogenesis of craniosynostosis : a translation of his original work. Plasti $\mathrm{R} r$ construction Surgery. 83:738-742.

Regelsberger J, Schmidt T, Busse B, I'erzen J, Tsokos M, Amling M, Beckmann F. 2010. Synchrotron-microcomputed $\mathfrak{t} \sim \boldsymbol{m}^{\mathrm{r}}$ aphy studies of normal and pathological cranial sutures: further insight. Jour $>1$ ol Neurosurgery: Pediatrics. 5: 238-242.

Sanchez-Lara PA, Carmichat. `L, Graham JM Jr, Lammer EJ, Shaw GM, Ma C, Rasmussen SA; National Birth Гerects Prevention Study.2010. Fetal constraint as a potential risk factor for craniosynostosis.American Journal Medecine Genetics A. 152A(2):394-400.

Sear HR. 1937. Some notes on craniostenosis. British Journal of Radiology.

Shipley RJ, Chapman SJ. 2010. Multiscale Modelling of Fluid and Drug Transport in Vascular Tumours. Bull. Math. Biol. 72: 1464-1491.

Slater B, Lenton KA, Kwan MD, Gupta DM, Wan DC, Longaker MT, 2008. Cranial sutures: a brief review. Plastic Reconstruction Surgery. 121(4) :170e-8e.

Tartaglia M, Bordoni V, Velardi F, Basile R. 1999. Fibroblast growth factor receptor 
mutational screening in newborns affected by metopic synostosis. Child's Nervous System. (8): 389-93.

Van der Vlugt JJ, van der Meulen JJ, Creemers HE, Verhulst FC, Hovius SE, Okkerse JM. 2012. Cognitive and Behavioral Functioning in 82 Patients with Trigonocephaly. Plastic Reconstruction Surgery. 130: 885-893.

\section{APPENDIX}

The specimen strain energy is expressed by equation (1a). $A_{-}=0_{1}$ Aing to figure $2 \mathrm{~b}$, angle $\alpha_{A}$ and curvature radius $r$ are expressed by equation (A1a) an $\downarrow$ ( $t, 1 \mathrm{~b})$ respectively. Tensile force $N_{x}$, shear force $T_{y}$ and ending moment $M_{z}$ are expres_d $\iota_{y}$ equation (A2). After substitution to equation (1a) and integration between $\alpha_{A}$ and $\pi / 2, U_{1 \mathrm{~s}}$ obtained and then derives once with respect to $F$. After factorisation, it gives equitiv. (1b) describing the general expression of modulus $E$ as a function of the mechaı: al response, i.e. $F / V$, and specimen geometrical properties, i.e. $b, h, s$, and $\delta$. Coefficient $\therefore$ is expressed by equation (A3).

$$
\begin{aligned}
& \alpha_{A}=2 \arctan (l / \delta)-\frac{\pi}{2} \quad \text { (a) } \quad r=l / \cos \alpha_{A} \quad \text { (b) } \\
& N_{x}=-\frac{F}{2} \cos (\alpha) \text { (a) } \quad T-\frac{F}{?} \cdot 1(\alpha) \quad \text { (b) } M_{z}=-\frac{F}{2}(l-r \cdot \cos \alpha) \quad \text { (c) } \\
& \lambda=\delta^{8} \cdot 3 s \cdot\left(\pi-2 \alpha_{A}\right)+\delta \cdot 84 s \cdot l+\delta^{6} \cdot\left(\pi-2 \alpha_{A}\right) \cdot\left(36 s l^{2}+h^{2}[s+2(1+v)]\right) \\
& +\delta^{5} \cdot\left(4 s l \cdot\left(h^{2}-45 l^{2}\right)-8 h^{2} l \cdot(1+v)\right)+\delta^{4} \cdot\left(\pi-2 \alpha_{A}\right) \cdot 2 l^{2} \cdot\left(33 s l^{2}+h^{2}[s+2(1+v)]\right) \\
& +\delta^{3} \cdot\left(-4 s l^{3} \cdot\left(h^{2}+27 l^{2}\right)+8 h^{2} l \cdot(1+v)\right)+\delta^{2} \cdot\left(\pi-2 \alpha_{A}\right) \cdot l^{4} \cdot\left(36 s l^{2}+h^{2}[s+2(1+v)]\right) \\
& +\delta \cdot\left(-12 s l^{7}\right)+3 s l^{8} \cdot\left(\pi-2 \alpha_{A}\right)
\end{aligned}
$$




\section{Conflict of interest}

Authors declare to have no conflict of interest. 
Biomechanics of scaphocephaly

P. Swider, F. Delanoë, F. Jalbert, S. Boetto, P. Assemat, E. Estivalèzes, F. Lauwers
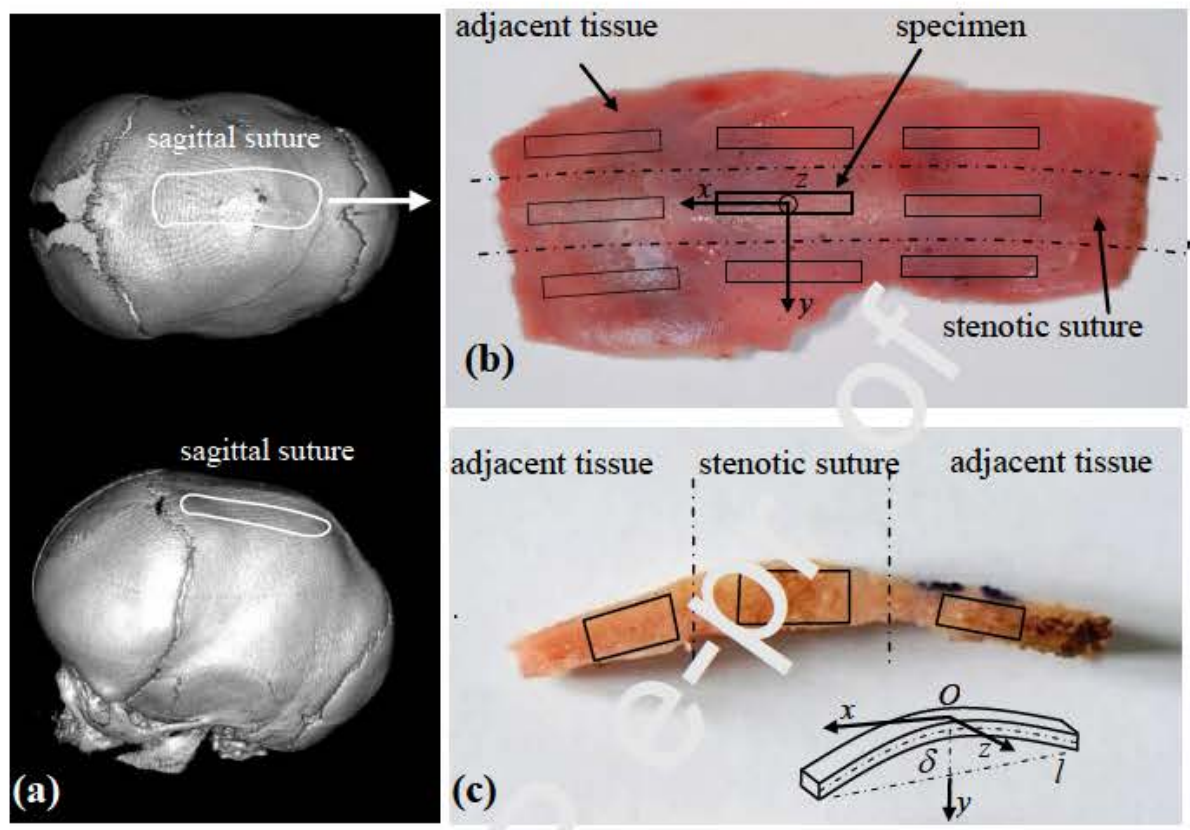

(b)

Figure 1 - (a) anatomy of an infant sr aj nocephalic skull; (b) a resected suture with locations of harvested specimens; (c) trar sv"se view of a specimen, natural curvature $\delta$ and local reference frame for tests. 
Biomechanics of scaphocephaly

P. Swider, F. Delanoë, F. Jalbert, S. Boetto, P. Assemat, E. Estivalèzes, F. Lauwers
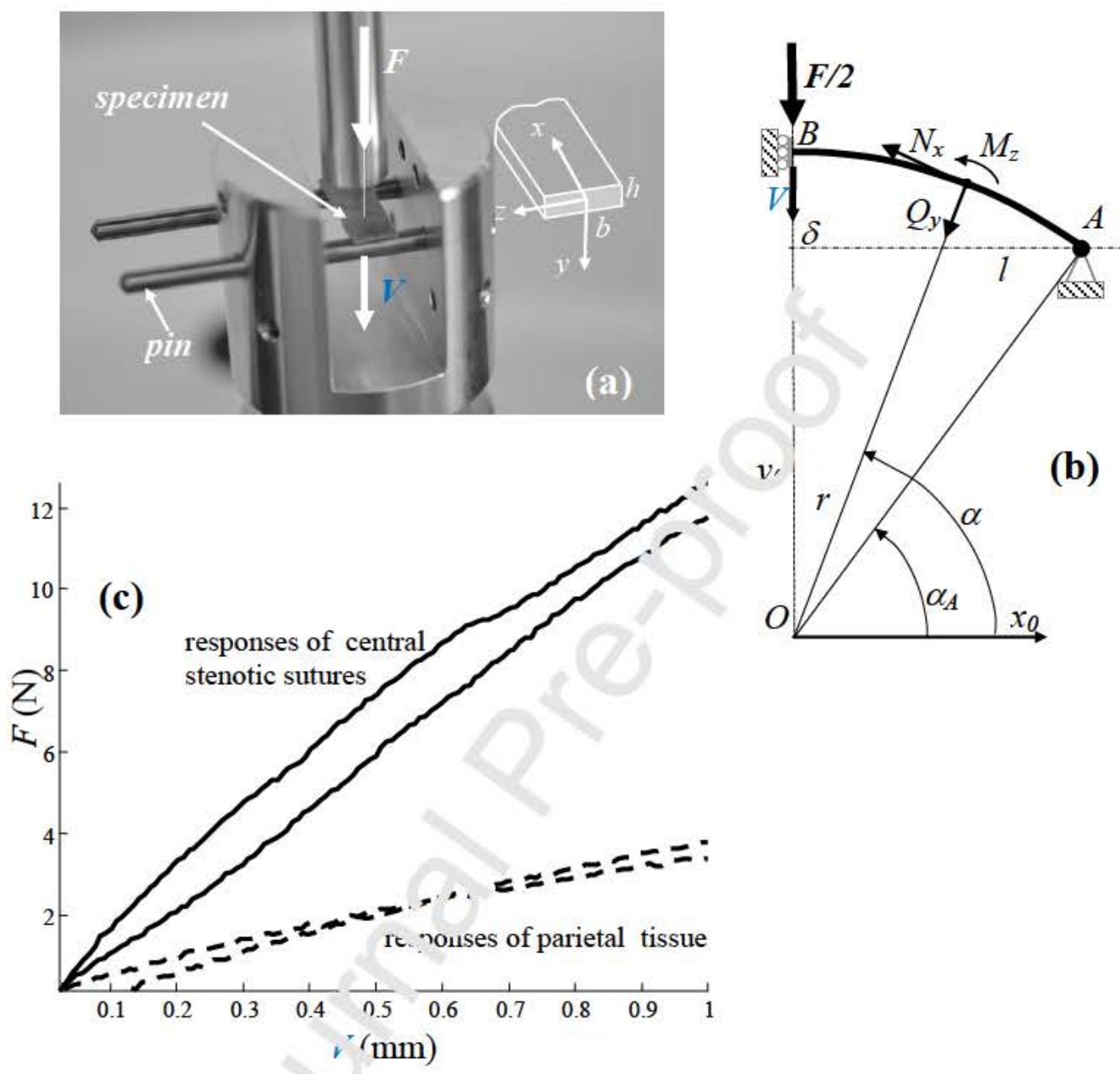

Figure 2 - (a) Three- oin s bending fixture, (b) Analytical mechanical model for test interpretation with $l$ : has: length of the specimen, $v$ : transverse displacement, $F$ : applied force, $r$ : specimen curvature, $\therefore$ natural curvature of the specimen, $N_{x}$ : normal force, $Q_{y}$ : shear force, $M_{z}$ : bending momentum, (c) mechanical response of specimens: (-) central stenotic suture $(2 l=30 \mathrm{~mm}, b=6 \mathrm{~mm}, h=2.5 \mathrm{~mm},(--)$ parietal tissue $(2 l=30 \mathrm{~mm}, b=6 \mathrm{~mm}, h=1.5 \mathrm{~mm})$. 
Biomechanics of scaphocephaly

P. Swider, F. Delanoë, F. Jalbert, S. Boetto, P. Assemat, E. Estivalèzes, F. Lauwers
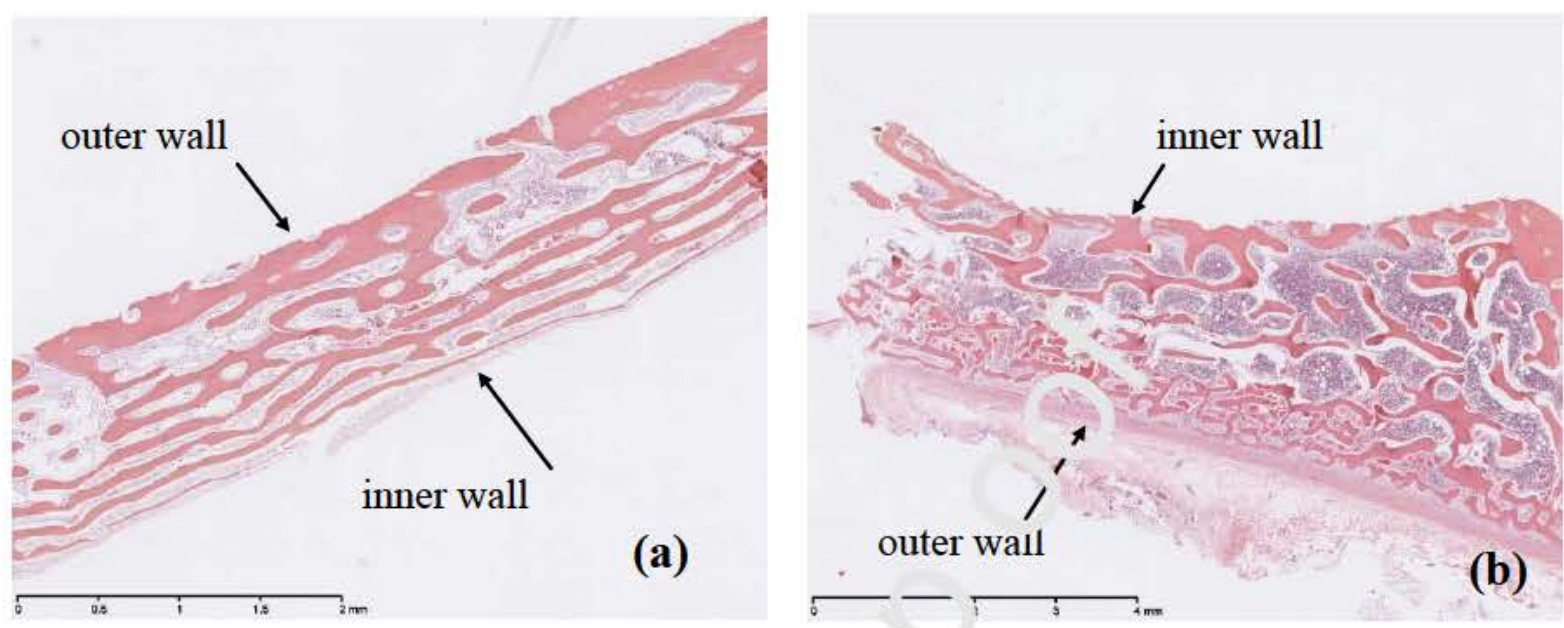

Figure 3: Histological slices: (a) parietal adjart", ti sue considered as control, (b) central stenotic suture considered as pathological ticst. 
Biomechanics of scaphocephaly

P. Swider, F. Delanoë, F. Jalbert, S. Boetto, P. Assemat, E. Estivalèzes, F. Lauwers
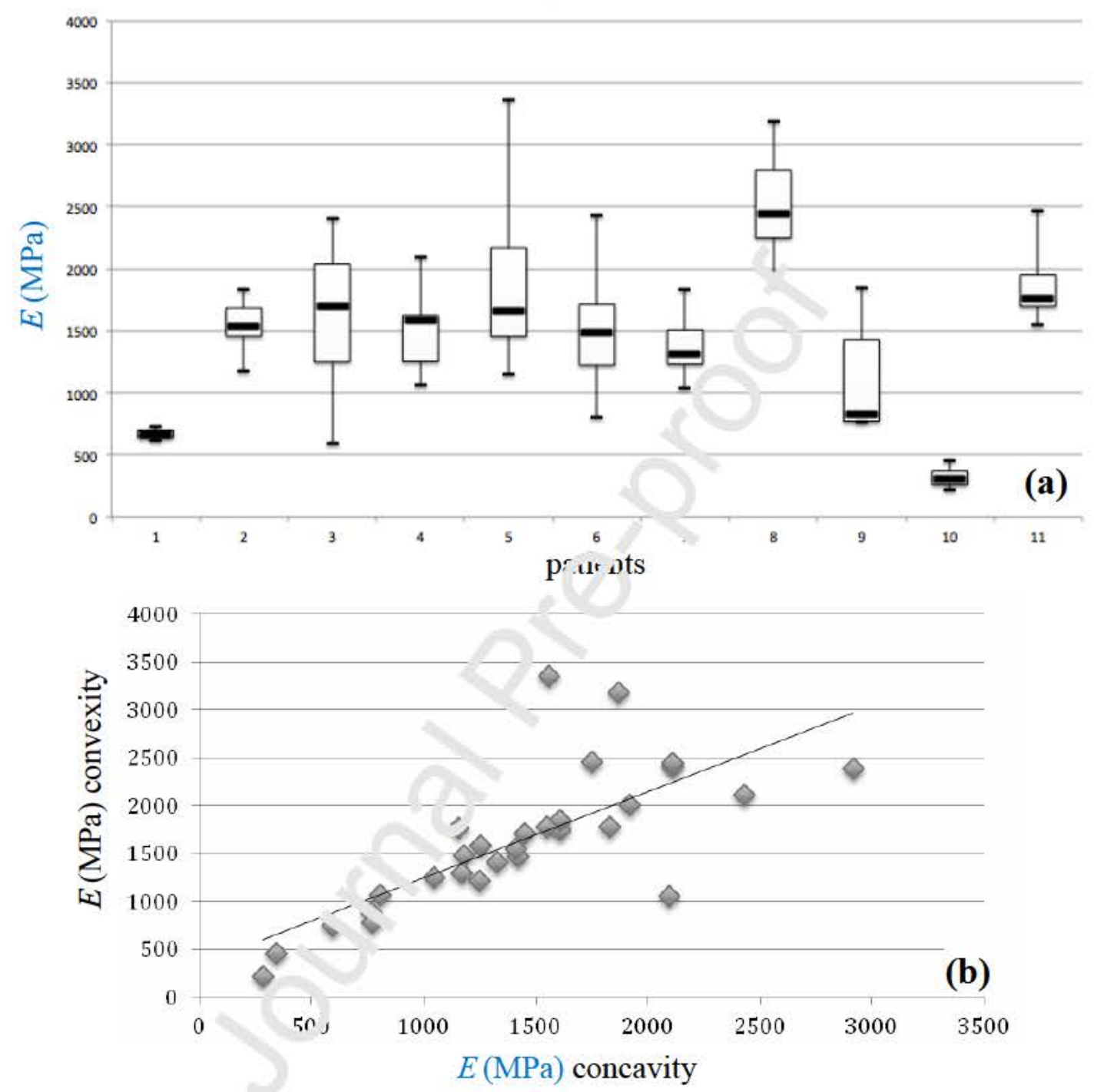

Figure 4 - Parietal adjacent tissue: (a) effective Young's modulus $E$ per patient, (b) correlation between $E$ obtained with loads applied on concave and convex sides. 
Biomechanics of scaphocephaly

P. Swider, F. Delanoë, F. Jalbert, S. Boetto, P. Assemat, E. Estivalèzes, F. Lauwers
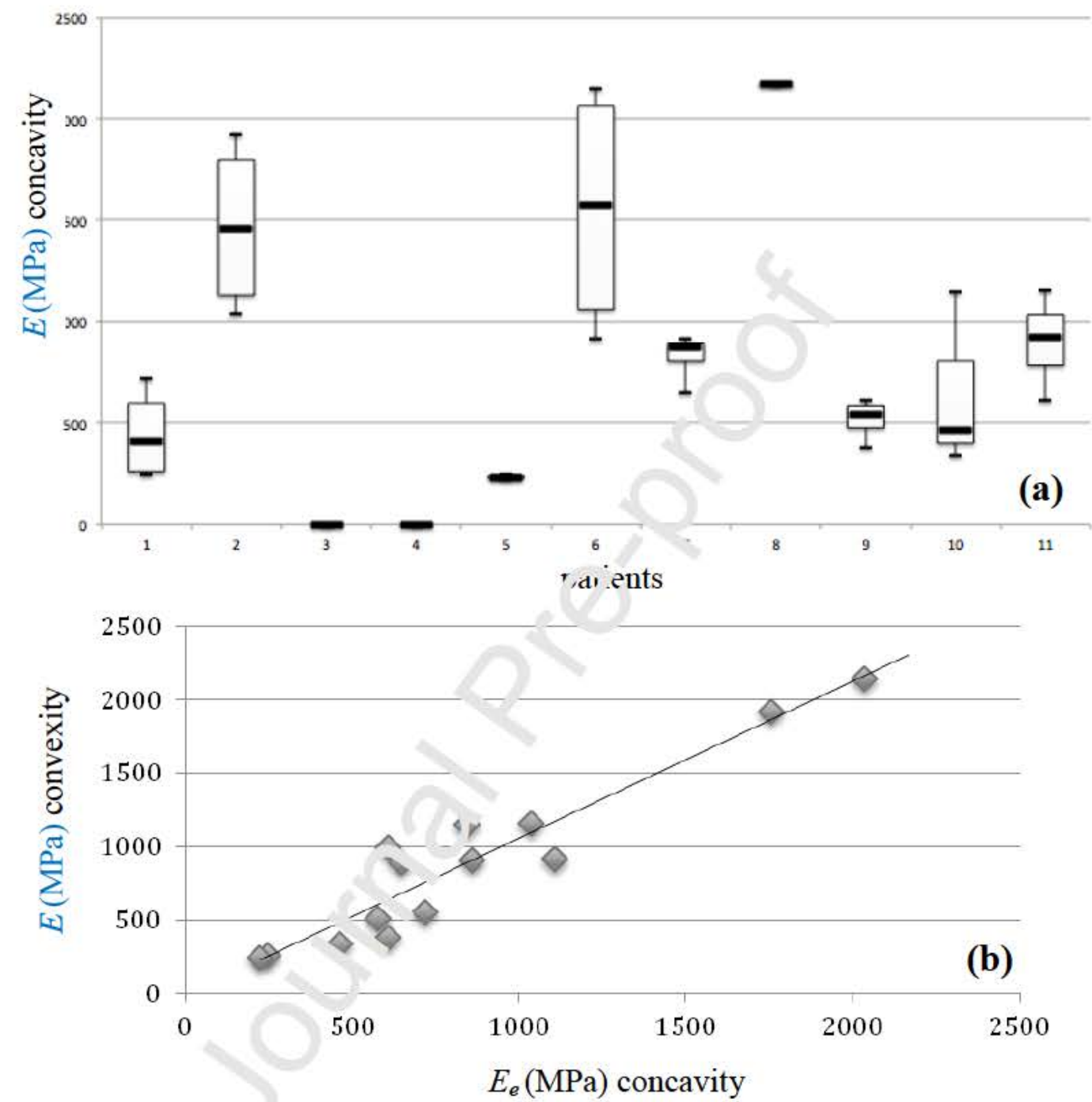

Figure 5 - Central stenotic sutures: (a) effective Young's modulus $E$ per patient, (b) correlation between $E$ obtained with loads applied on concave and convex sides. 
Highlights

- $\quad$ Premature closure of sutures causes craniosynostosis and skull deformity.

- $\quad$ Fused sutures were stiffer and Young's modules were lower than normality.

- Exploration of suture mechanical response may contribute to craniostenosis etiology. 